\title{
A decade of cell therapy clinical trials (2000-2010)
}

\section{"An understanding of the clinical trial landscape provides an insight into the likely future form of the industry, as well as the infrastructural provisions and timescales that need to be provided in order to facilitate its unimpeded development and growth."}

\section{KEYWORDS: cell therapy $\approx$ clinical trials $\approx$ ClinicalTrials.gov $\approx$ commercialization - regulation $=$ translation}

\section{Summary}

The cell therapy industry (CTI) is presently a small but potentially rapidly growing new global healthcare sector. Success is totally dependent on resolving a number of factors unique to cells as therapies, including: manufacturing, enabling technologies, regulation, reimbursement and essential infrastructure. To understand how to solve these challenges in a timely and cost-effective manner, it is essential to be able to forecast the size and resource demands of the sector for a least the next decade. Due to the highly regulated nature of medicines, one predictive method is to analyze the candidate therapies that are currently undergoing clinical trials (i.e., the future pipeline). A search was performed on the website ClinicalTrials.gov [101] using the embedded search engine and key terms relating to 'cell therapy'. A total of 17,362 files were extracted (27 June 2010) and individually checked for relevance using the British Standard Institute (BSI) definition of 'cell therapy' [1]. The resulting 2724 trials were then categorized and core information collated, including: trial phase, cell source (autologous/allogeneic), current activity of the trial and responsible national regulatory agency. Key results included: near equal numbers of autologous (46\%) and allogeneic (41\%) trials; many of the trials are in the later stages - Phase I (49\%), Phase II (40\%) or Phase III (10\%); and there are significantly larger numbers of transient cell therapies $(50 \%)$ as opposed to permanent cell replacement $(5 \%)$. This is the first time that the number and composition of all the cell therapy trials on ClinicalTrials.gov has been researched at the level of individual entries, analyzed and published. These data have important planning and resource allocation implications for translational scientists, clinicians, healthcare providers, businesses and governments.

\section{Background}

The two questions, 'how many cell therapy clinical trials are there currently?' and 'what is their composition?' are frequently heard when discussing progress in the cell therapy sector. With a number of official databases available on the internet, such as ClinicalTrials.gov [101], the answer should only be a few clicks away. Unfortunately, the reality is that obtaining accurate figures from the ClinicalTrials.gov database for a platform technology such as cell therapy requires a more sophisticated approach. The research described in the following text examined, at an individual level, every cell therapy trial in the ClinicalTrials.gov database, using a combination of an initial search with key terms to provide a coarse screen of the entire database, followed by an exceptionally high level of manual sorting of each of the listed results. The 'cleaned-up' data (i.e., those entries confirmed to be true cell therapy) were then analyzed to produce the first survey of the number and composition of the entire ClinicalTrials.gov cell therapy clinical trials listing.

The CTI is now firmly established as a billiondollar business that is entirely distinct from the existing pillars of healthcare [2]: conventional pharmaceuticals, biologics and medical devices. An understanding of the clinical trial landscape provides an insight into the likely future form of the industry, as well as the infrastructural provisions and timescales that need to be provided in order to facilitate its unimpeded development and growth.

It is undoubtedly challenging to accurately predict the pace and future composition of

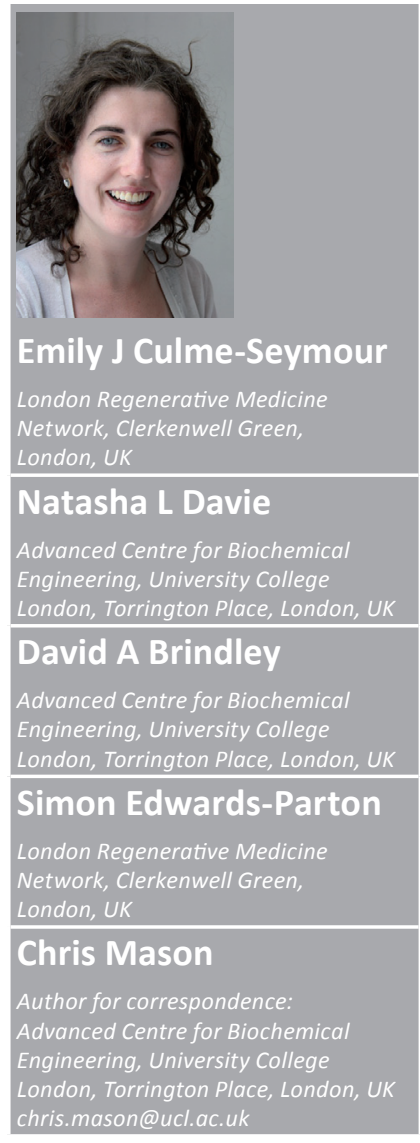

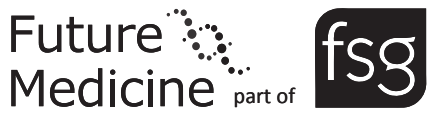


most industries, and thus how best to prepare in advance with any real degree of certainty. This is largely due to the majority of commercial sectors exhibiting short product cycles and commercialization routes. For example, web-based technologies can develop from ideas to commercial successes in a matter of months, with minimal start-up capital or resources required. Therefore, the product can already be a runaway success before any analysis or predictions have been finalized. By comparison, in the healthcare sector, product cycles are typically longer, due to the protracted and costly nature of $\mathrm{R} \& \mathrm{D}$, clinical trials, regulation, clinician/healthcare provider adoption and reimbursement [3]. From a regulatory perspective, clinical trials are mandatory, and from a business perspective, they are expensive, have a long duration and are high-risk. Nonetheless, and arguably most importantly, from a patient perspective, clinical trials are essential for therapies to be safe and efficacious. The clinical trials critical path is, therefore, unavoidable, but it can be used beneficially in predicting the potential future industry outputs in terms of depth and breadth of forthcoming products. For example, from historical data, the attrition rates for potential new drugs moving from one phase to the next is known, and thus forecasts for pharmaceuticals and biotechnology can be deduced $[4,5]$.

The CTI is fortunate that it can now boast several products that are achieving significant reimbursement, including its first blockbuster product, Dendreon's Provenge ${ }^{\circledR}[6]$, reimbursed at US $\$ 93,000$ per patient. Its approval by the US FDA on 29 April 2010 marked a momentous landmark for the industry. Although this approval was of major significance, many more trials are underway and, if successful, capable of delivering numerous future block- and nichebusters. However, the key questions remain: how many and what are they?

\section{Introduction}

An analysis of the current CTI clinical trial landscape is rather like a 'sneak peek' onto the desk of the Chair of the City Planning Commission, charged with managing the development of a new city. Not all the plans submitted will be accepted; some will be outright rejected, while others will be accepted with revisions. However, these early plans will bear some resemblance to the final outcome and construction. Thus, by taking a look at the desk of the CTI's equivalent of the City Planning Commission, the regulator (e.g., the FDA), an early glimpse can be obtained into the probable size and composition of the cell therapy space for the coming decade.

The website ClinicalTrials.gov was established in February 2000 in response to Section 113 of the 1997 FDA Modernization Act [7,102] as a free public service of the US NIH developed by the National Library of Medicine. All clinical trial sponsors must report details of their studies using a standard web-based template which is then uploaded to the website. The sponsor, federal or private, then remains responsible for updating the information provided as the trial progresses. However, no studies are ever removed from the database [National Library of Medicine Customer Service, Pers. Comm.].

Unfortunately, despite the good intentions of the Modernization Act, compliance was variable [7]. Therefore, on 27 September 2007, President George W Bush signed into law H.R. 3580, the FDA Amendments Act (FDAAA) of 2007 [103]. Under Section 801, details of all clinical trials "other than a Phase I clinical investigation" must be made publicly available on ClinicalTrials.gov. The FDAAA also required sponsors to post the results of their clinical trials on the ClinicalTrials.gov website. Furthermore, a number of trials conducted in the rest of the world are also available on the site, on a voluntary basis only $[7,8]$. Thus, this website probably represents the most significant source of clinical trial data worldwide. The only other clinical trial database of note available on 27 June 2010 was the WHO International Clinical Trials Registry Platform (ICTPR) [104]. On searching ICTRP on 27 June 2010, there were less than 100 trials returned using the BSI definition of 'cell therapy' [1]. There was also major overlap between the ICTRP and ClinicalTrials.gov data on cell therapy trials. The EU Clinical Trial Register [105] was launched after our data collection point (22 March 2011). Since March 2012, the EU Clinical Trial Register is available through the WHO ICTRP. Likewise, the UK Clinical Trials Gateway [106] was launched 25 April 2012.

One issue that frequently arose during this research was the need for naming standards. Standardized nomenclature, such as the ones suggested by the US Adopted Name Council Cellular Therapies Working Group [107] and the preliminary thinking of the US Pharmacopeial Convention Biologics \& Biotechnology: Cell, Gene, and Tissue Therapies Expert Committee on tissue and tissue-based products [108] would ensure that the name of the product would provide not only the product's main components, 
but also vital information regarding the source of cells, along with the way it was processed.

\section{Methodology}

On 27 June 2010, a search for the criterion 'cell therapy' was conducted on the ClinicalTrials.gov website, using the website's embedded search tool. This produced 17,362 results, all of which were extracted for data analysis.

Individually, all 17,362 results from the data were then manually checked in order to remove duplicate entries and to identify and select only the cell therapy trials. The term 'cell therapy' was defined using the BSI definition, "Cell therapy is the therapeutic application of cells regardless of cell type or clinical indication - a platform technology" [1]. This resulted in the selection of the 2724 cell therapy clinical trials held on the ClinicalTrials. gov database. At this stage, 799 studies were identified as 'completed', 'withdrawn' or 'terminated', leaving 1925 cell therapy trials as ongoing. These were categorized on ClinicalTrials.gov as 'active, not recruiting', 'available for expanded access', 'enrolling by invitation only', 'no longer available for expanded access', 'not yet recruiting', 'recruiting' or 'suspended'. All 2724 cell therapy trials were then mined for additional details including: whether the cells remained permanently or not in the patient; phase of the trial; source of the cells (e.g., autologous, allogeneic or xenograft); and geographical region of the trial.

The ongoing trials (the basis of our analysis) were individually categorized using the decision tree depicted in Figure 1, deploying the definitions shown in Table 1. Wherever possible, definitions were taken from acknowledged sources - the BSI-produced Cell Therapy and Regenerative Medicine Glossary [1] and ClinicalTrials.gov [101].

Each trial was assigned to only one main category. Conventional grafts (e.g., tissue/organ, bone marrow, mobilized blood progenitor cells or cord blood transplants) were categorized as a major category in their own right compared with advanced cell-based therapies. The secondary gates within the main categories, 'permanent implantation' and 'transient dosing', were chosen to distinguish between potential products that would be closer to conventional pharmaceutical

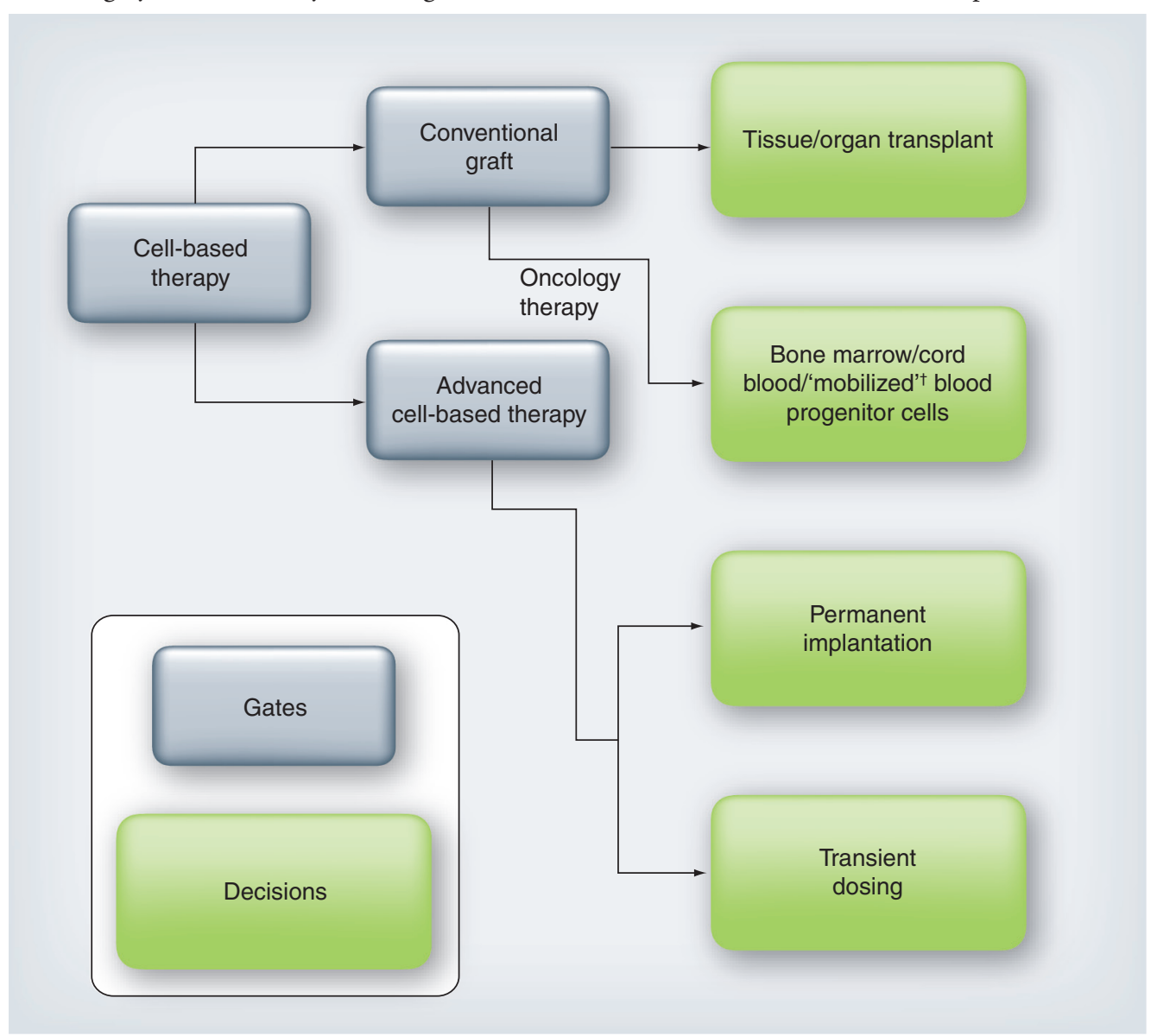

Figure 1. The decision tree structure used to determine the specific category for all 2724 cell therapy-based clinical trials on ClinicalTrials.gov on 27 June 2010.

${ }^{\dagger}$ No other factor except GCSF used to mobilize. 


\section{Table 1. Glossary of terminology.}

\section{Terminology}

Allogeneic

'Associated/enabling'

Autologous

'Autologous/allogeneic'

Cell therapy

Conventional graft

Expanded access

Interventional study

Observational study

Permanent implantation therapy

Quality-of-life trial (supportive care trial)

Recruitment status

\section{Definition}

Where the donor and recipient are different individuals

Trials that are not directly focused on developing cells as therapies, but are conducting research that will contribute to the advancement of the sector

Where the donor and recipient are the same individual

Trials involving the use of both autologous and allogeneic cells, either as a potential combination therapy or where autologous and allogeneic approaches are being directly compared

Therapy in which cells are administered to the body to the benefit of the recipient

Tissue/organ grafts and bone marrow, cord blood or mobilized blood progenitor cells to replace bone marrow with healthy bone marrow stem cell post-chemo-/radio-therapy

Refers to any of the US FDA procedures (compassionate use, parallel track and treatment IND) that distribute experimental drugs to participants who are failing on currently available treatments for their condition and also are unable to participate in ongoing clinical trials

Study in human beings in which individuals are assigned by an investigator based on a protocol to receive specific interventions. Subjects may receive diagnostic, therapeutic or other types of interventions. The assignment of the intervention may or may not be random. The individuals are then followed and biomedical and/or health outcomes are assessed

Study in human beings in which biomedical and/or health outcomes are assessed in predefined groups of individuals. Subjects in the study may receive diagnostic, therapeutic or other interventions, but the investigator does not assign specific interventions to the subjects of the study

Cell therapies, where the implanted cells and/or their progeny remain in vivo for an extended period (typically years)

Trials that explore ways to improve comfort and quality of life for individuals with a chronic illness

Indicates the current stage of a trial, whether it is planned, ongoing or completed. Possible values include:

- Not yet recruiting: participants are not yet being recruited or enrolled

- Recruiting: participants are currently being recruited and enrolled

- Enrolling by invitation: participants are being (or will be) selected from a predetermined population

- Active, not recruiting: study is ongoing (i.e., patients are being treated or examined), but enrollment has completed

- Completed: the study has concluded normally; participants are no longer being examined or treated (i.e., the last patient's last visit has occurred)

- Suspended: recruiting or enrolling participants has halted prematurely but will potentially resume

- Terminated: recruiting or enrolling participants has halted prematurely and will not resume; participants are no longer being examined or treated

- Withdrawn: study halted prematurely, prior to enrollment of first participant

Transient dosing therapy Cell therapies, where the implanted cells and/or their progeny have a limited lifespan/'half-life' in vivo (typically days/weeks)

Xenograft

Where the donor and recipient belong to different species

Wherever possible, definitions were taken from acknowledged sources: the British Standard Institute-produced Cell Therapy and Regenerative Medicine Glossary [1] and ClinicalTrials.gov [101].

IND: Investigational New Drug.

and biotechnology models of therapeutic delivery (i.e., transient residence in the body - days to a few weeks) and those cell-based therapies that would reside more permanently (i.e., for a number of years) in the patient.

Since the driver of this research was to quantify potential advanced cell therapies that, if successful in their clinical trials, would contribute to the growing cell therapy industry's revenues, there are, therefore, two important caveats to note when viewing the data. First, a number of trials were classified as 'associated/enabling' compared with actual interventional therapies. Associated/enabling trials are defined as "trials that are not directly focused on developing cells as therapies, but are conducting research that will contribute to the advancement of the sector" (Table 1). Such trials include diagnostic trials (to find better tests for diagnosing a particular condition), screening trials (test the best way to detect certain conditions) and quality-of-life trials (explore ways to improve quality of life), for example, trial NCT00348959 "...to evaluate the psychological effect of 'Open Window' (ambient virtual window) on the consequences of long-term isolation on patients undergoing stem cell transplantation treatment of hematological malignancies." While such trials are of value in helping facilitate the field, they are not an 
interventional therapy trial that could eventually result in a regulated cell therapy product. Second, cell therapies categorized as 'conventional' are in general not directly related to the emerging cell therapy industry, with the exception of the recent mandatory requirement for public cord blood banks to go through the FDA-approval process, for example, for the product Hemacord ${ }^{\mathrm{TM}}$ [9].

For the few database entries that did not supply data regarding the exact clinical trial phase, the entry was carefully scrutinized, and associated websites and other related information were investigated in order to make an informed decision regarding phase. Thus, Phase 0 - and Phase I/II-listed studies were assigned to the 'Phase I' category, since safety was noted as their primary end point. Likewise, trials listed as Phase II/III were designated as Phase II.

Finally, when determining the source of the cells, the vast majority of trials specified either autologous or allogeneic cells. For the few database entries that did not supply cell type data, other sources of information were again carefully scrutinized, in order to make an informed judgment. Crucially, for the small number of trials reporting the cell source as 'autologous and allogeneic combination therapy' or 'autologous versus allogeneic comparison studies', these were dual-categorized; for example, NCT01040026 is a Phase I trial looking at allogeneic and autologous cells coinfused as an experimental treatment for multiple myeloma.

It is important to note that while the authors fully appreciate that the above methodology is not perfect, it does, however, enable a pragmatic foundation upon which to start to quantify the cell therapy trial space. Evaluating the enormity and complexity of the ClinicalTrials.gov database given its known limitations is certainly challenging [10-12], although the authors hope to have demonstrated its benefits, albeit after needing a highly time-consuming manual exercise to find the correct entries. Similar challenges have been reported by other authors examining the database in general [12-16].

\section{Results \& discussion}

Figures 2-6 provide the first indication of the size and composition of the cell therapy clinical trial landscape. The underlying data were extracted from ClincialTrials.gov on 27 June 2010, for the period of February 2000-June 2010.

Figure 2 shows the distribution of the stages of all cell therapy clinical trials for the period of February 2000-June 2010. It is important to note that a candidate cell therapy can be

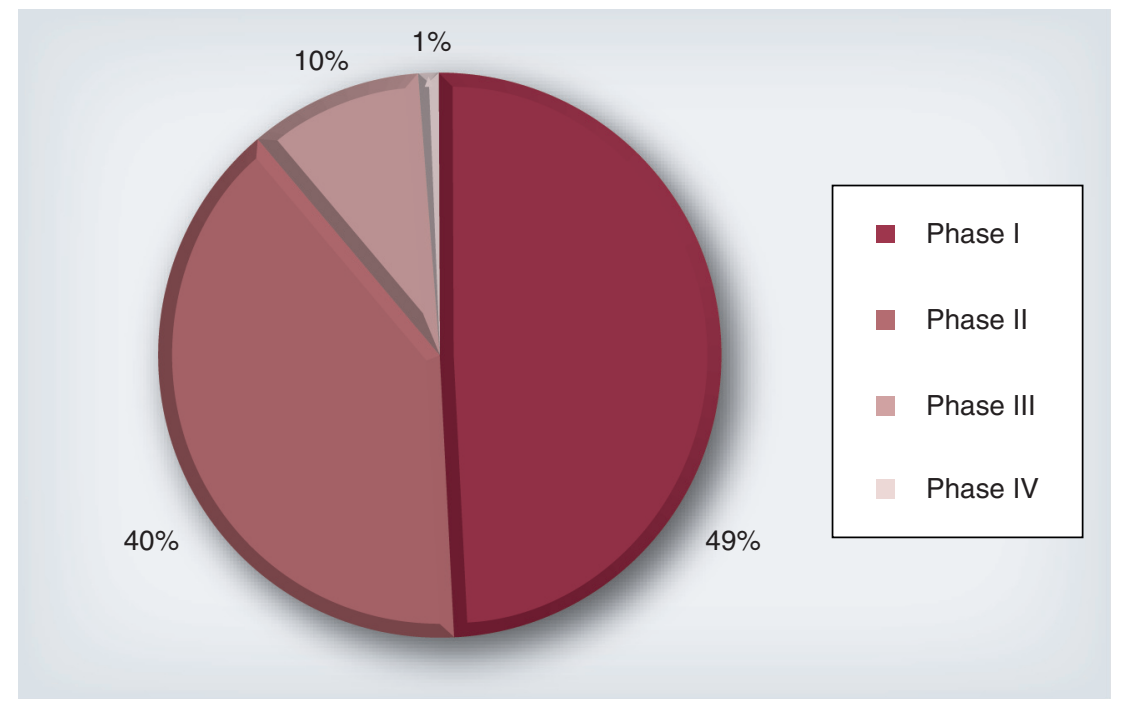

Figure 2. Proportion of cell therapy trials in Phase I-IV for the period of February 2000-June 2010.

present in one or more phases, depending upon its progress during the decade; a good example would be Prochymal ${ }^{\circledR}$ (Osiris Therapeutics) for Crohn's disease. ClinicalTrials.gov lists a number of Phase II and III studies for this potential therapy including NCT00294112 (Phase II commenced in February 2006) and NCT00482092, NCT00543374 and NCT01233960 (Phase III studies commenced in May 2007, October 2007 and September 2010, respectively).

Given that under Section 801 of FDAAA details of all clinical trials "other than a Phase I clinical investigation" must be made publically available on the website, the figure of 1325 for

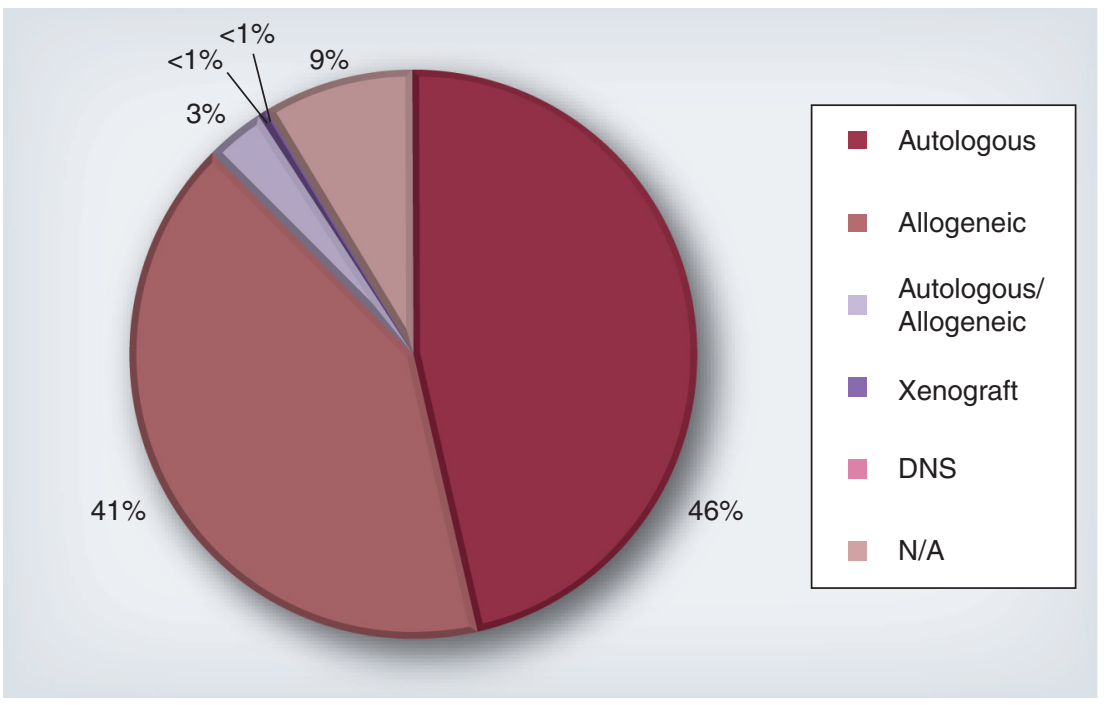

Figure 3. Proportion of cell therapy trials that were designated autologous, allogeneic, 'autologous/allogeneic' and xenograft for the period of February 2000-June 2010. DNS refers to trials that did not state the cell type used and N/A refers to the 236 'associated/enabling' trials, since these did not necessarily involve the administration of a specific cell type.

DNS: Did not specify; N/A: Not applicable. 


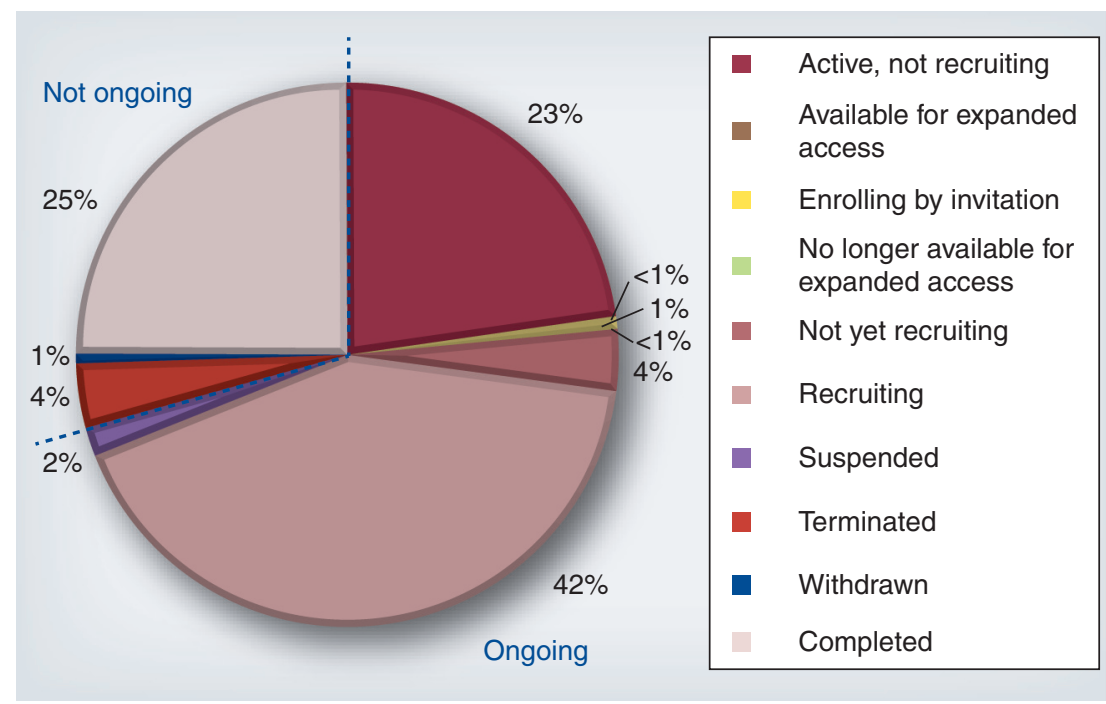

Figure 4. The status of cell therapy trials registered on ClinicalTrials.gov during the period of February 2000-June 2010.

Phase I studies will, therefore, probably be an underestimate. Nonetheless, in our analysis of the available data, an approximately similar proportion of trials are in the Phase II stage (40\%) as are in Phase I (49\%). The relatively small number of Phase III trials (275) in the main reflects the immaturity of the cell therapy platform technology as a whole, rather than accurately portraying the likelihood of a given product progressing through the entire trial process. It is simply too early in the development life-cycle to know if the rates of attrition for cell-based therapies are better or worse than for small molecule pharmaceuticals or biologics. A more in-depth study is required once the sector has progressed to a more stable state; however, prima facie, the attrition rate appears significantly less for cell-based

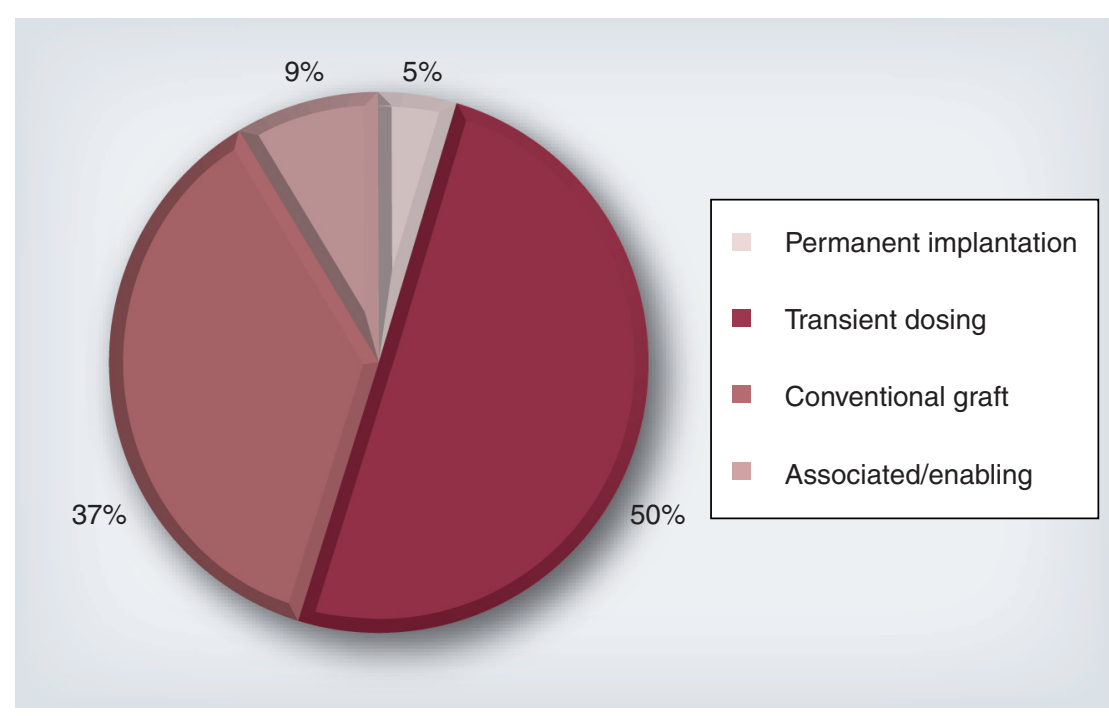

Figure 5. High-level mode of action of cell therapy trials registered on ClinicalTrials.gov during the period of February 2000-June 2010. therapies than for pharmaceuticals and biologics. The current metrics of success for drugs is in the order of Phase I (63\%), Phase II (33\%) and Phase III (55\%), with an industry average of Phase I to regulatory approval of 9\% (using compounded probabilities) [109]. It is pure speculation only, but if this overall percentage chance of success is applied to the cell therapy clinical trials in progress and assuming all are in Phase I (avoiding the issue of the same trial in more than one phase for the reason stated above), this would suggest that over 170 of the current cell therapies listed as ongoing on ClinicalTrials.gov could make it through the regulatory approval process over the next 15 years.

The proportions of autologous and allogeneic cell therapies in development for the period of February 2000-June 2010 are presented in Figure 3. Overall, these two approaches are approximately equal. A tiny proportion of trials, termed 'autologous/allogeneic' in the figure, use both autologous and allogeneic cells. The similar proportions of autologous and allogeneic cell trials does not indicate a clear preference, despite the very different business models, that is, service industry versus universal product, respectively. This, in part, mirrors the diversity of the trial sponsors, which include both clinicians and companies. Only two trials used xenograftbased materials (including sole administration of xenograft cells, as well as human cells grown in association with animal cells). This may reflect a general lack of confidence in developing new xenograft cell products owing to the demise of the xenograft transplant companies in the early part of the century, due to concerns over the potential transmission to patients of porcine endogenous retroviruses [17]. However, it is important to note that a number of xenograft therapies are either already in the clinic (e.g., Epicel ${ }^{\circledR}$, Genzyme [18]) or making good progress towards the clinic (e.g., Diabecell ${ }^{\circledR}$, Living Cell Technologies; NCT00940173).

Figure 4 shows, for the period of February 2000-June 2010, the split between 'ongoing' (as defined above) and 'completed', 'withdrawn' or 'terminated' trials and their subcategories, as of 27 June 2010. The majority of trials are in progress; for example, $42 \%$ of all trials are recruiting, with a further $23 \%$ active but not recruiting, hence these trials are underway and in follow-up mode.

The distribution of cell therapy clinical trials for the period of February 2000-June 2010 for the four main categories - permanent, transient, conventional graft and associated/enabling - is 
displayed in Figure 5. A total of $50 \%$ of the trials involved cells that are typically eliminated in a number of days/weeks after implantation that is, only transiently surviving in vivo. Thus, their mechanism of action is not as a permanent replacement cell. Conversely, only $5 \%$ of therapies were defined as a permanent implantation, where the administered cells or their progeny remain in vivo for a number of years. A decade ago, the vast majority of cell therapy trials would have been conventional grafts, but with the growth of advanced cell therapies, today they represent only approximately a third of all cell-based therapy trials $(37 \%)$.

The location of the registered health authority for the cell therapy clinical trials for the period of February 2000-June 2010 is shown in Figure 6. Since legislation in the USA makes registration compulsory for all FDA-authorized studies, it is not unsurprising that a large proportion of the total number of trials $(72 \%)$ are registered with the FDA, while only $23 \%$ are specified as solely from outside of the USA. However, this is not absolutely indicative of the location of the trial, since registering the trial with the FDA might not necessarily mean the trial is carried out in the USA, for example in the case of multicenter multinational trials. Trials from over 35 different countries, including Australia, France, Germany, India and the UK, have been voluntarily registered with ClinicalTrials.gov. On a word of caution, it was apparent that a few potential stem cell tourism 'trials' were registered with the site probably in order to gain 'credibility' and status by association.

\section{Endnote}

Since the point of extraction of our data, a number of other researchers have endeavored to analyze the cell therapy clinical trials space. A list of active Phase II/III and III commercial cell therapy clinical trials taking place around the world is available online on the Cell Therapy Blog [110]. The data were first made available in December 2011 and have been regularly updated. As of 1 May 2012, there were 40 latestage commercial trials being undertaken by 29 companies. A similar ratio of the number of autologous (48\%) and allogeneic (52\%) trials is found within this commercial subset to that shown in this paper. An analysis of the Advanced Therapy Medicinal Products (ATMP) trials taking place in Europe has also been recently published. The ATMP data, containing both cell and gene therapies, were obtained from the EU Drug Regulating Authorities Clinical

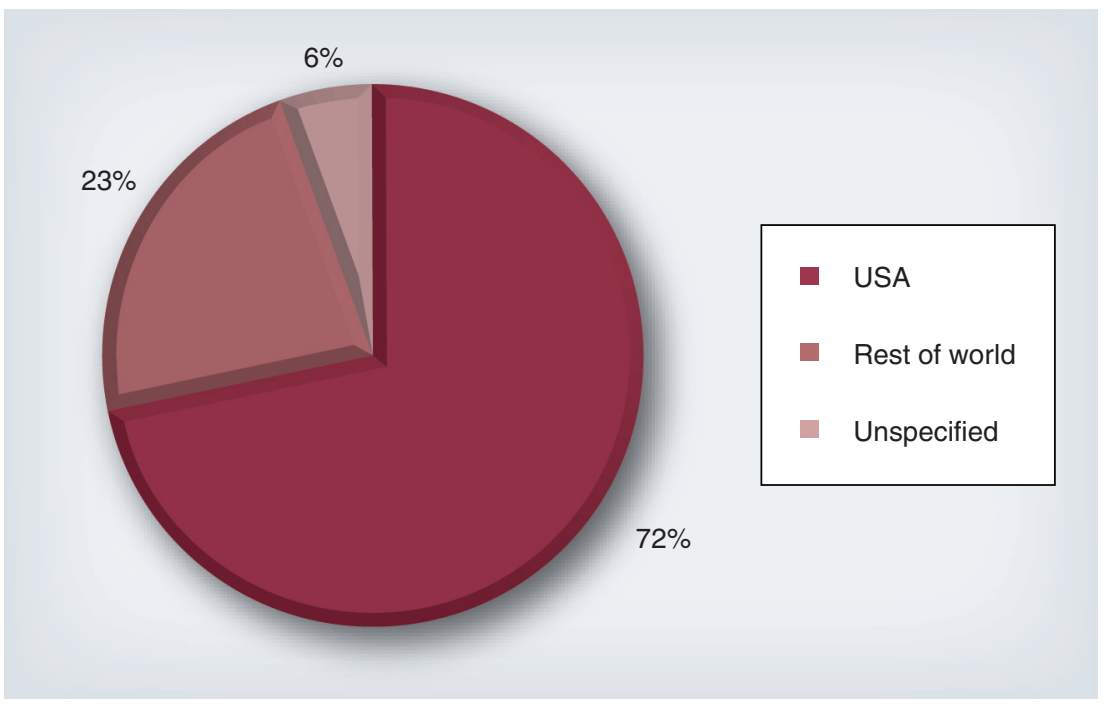

Figure 6. Cell therapy trial registrations by healthcare authority for the period of February 2000-June 2010.

Trials (EudraCT) database, which lists 318 ATMP trials performed between 2004 and 2010, with 142 types of cell-based therapies being developed [19]. The authors found that the sponsors $(n=173)$ of the ATMP clinical trials - academia, charity and industry - were in the ratio of 5:1:4, respectively. Additionally, the numbers of ATMPs in the different trials phases - Phase I, II and III - were 112, 144 and 46, respectively (adjusted to match the methodology of this paper). The overall composition of the EudraCT database again is similar to that of the ClinicalTrials.gov database, albeit over a shorter time frame (6 compared with 10 years); however, the overall number, even taking into account the shorter time frame, is significantly less.

\section{Conclusion}

This paper contains the first comprehensive analysis of the cell-based therapy clinical trials registered on the ClinicalTrials.gov database. The data presented include interventional, observational and expanded access entities from the very start of the database in 2000 up until 27 June 2010. By meticulously going through each entry on a one-by-one basis, and if missing important information or ambiguous, crossreferencing with other sources, a highly granular analysis of the cell therapy trials space has been produced. Overall, these data are highly encouraging for the emerging cell therapy industry, given the early stage of the technology platform in its life-cycle, total number of trials, the spread of clinical trial phases and the range of medical indications. Regular updating and further analysis and extrapolation of the data 
will enable forecasting of the future resources and infrastructure requirements, together with their timescales. These projections will be essential in order to avoid future bottlenecks and thus accelerate the growth of this important new healthcare sector.

\section{Financial \& competing interests disclosure}

C Mason is Principal Investigator and DA Brindley,

EJ Culme-Seymour, NL Davie and S Edwards-Parton are investigators on the British Regen Industry Tool Set project funded by the Technology Strategy Board under their Regenerative Medicine Program: Value Systems and Business Modelling. The authors have no other relevant affiliations or financial involvement with any organization or entity with a financial interest in or financial conflict with the subject matter or materials discussed in the manuscript apart from those disclosed.

No writing assistance was utilized in the production of this manuscript.

\section{References}

1 Cell therapy and regenerative medicine glossary. Regen. Med. 7(3 Suppl.), S1-S124 (2012).

2 Mason C, Brindley DA, Culme-Seymour EJ, Davie NL. Cell therapy industry: billion dollar global business with unlimited potential. Regen. Med. 6(3), 265-272 (2011).

3 Mason C, Manzotti E. The translation cycle: round and round in cycles is the only way forward for regenerative medicine. Regen. Med. 5(2), 153-155 (2010).

4 Dimasi JA, Feldman L, Seckler A, Wilson A. Trends in risks associated with new drug development: success rates for investigational drugs. Clin. Pharmacol. Ther. 87(3), 272-277 (2010).

5 Kaitin KI, Dimasi JA. Pharmaceutical innovation in the 21st century: new drug approvals in the first decade, 2000-2009. Clin. Pharmacol. Ther. 89(2), 183-188 (2011).

6 Arlen PM, Wood LV. Prostate cancer vaccines: moving therapeutic vaccination forward in the post-Provenge era. Expert Rev. Vaccines 11(3), 287-302 (2012).

7 Ross JS, Mulvey GK, Hines EM, Nissen SE, Krumholz HM. Trial publication after registration in ClinicalTrials.gov: a crosssectional analysis. PLoS Med. 6(9), e1000144 (2009).

8 Miller JD. Registering clinical trial results: the next step. JAMA 303(8), 773-774 (2010).

9 Allison M. Hemacord approval may foreshadow regulatory creep for HSC therapies. Nat. Biotechnol. 30 (4), 304 (2012).

10 Viergever RF, Ghersi D. The quality of registration of clinical trials. PLoS One 6(2), e14701 (2011).
11 Zarin D. Newsmaker interview: Debora Zarin. Unseen world of clinical trials emerges from U.S. database. Interview by Eliot Marshall. Science 333(6039), 145 (2011).

12 Zarin DA, Tse T, Williams RJ, Califf RM, Ide NC. The ClinicalTrials.gov results database - update and key issues. $N$. Engl. J. Med. 364(9), 852-860 (2011).

13 Wyler Von Ballmoos M, Oliveira C. The ClinicalTrials.gov results database. N. Engl. J. Med. 364(22), 2169; author reply 2170 (2011).

14 Magee LA, Menzies J. The ClinicalTrials.gov results database. N. Engl. J. Med. 364(22), 2169; author reply 2170 (2011).

15 Camilleri M. The ClinicalTrials.gov results database. N. Engl. J. Med. 364(22), 2169; author reply 2170 (2011).

16 Viergever RF, Ghersi D. The ClinicalTrials. gov results database. N. Engl. J. Med. 364(22), 2169-2170; author reply 2170 (2011).

17 Dorey E. PERV data renew xeno debate. Nat. Biotechnol. 18(10), 1032-1033 (2000).

18 Mason C, Manzotti E. Regenerative medicine cell therapies: numbers of units manufactured and patients treated between 1988 and 2010 . Regen. Med. 5(3), 307-313 (2010).

19 Maciulaitis R, D'Apote L, Buchanan A, Pioppo L, Schneider CK. Clinical development of advanced therapy medicinal products in Europe: evidence that regulators must be proactive. Mol. Ther. 20(3), 479-482 (2012).

\section{Websites}

101 ClinicalTrials.gov. www.ClinicalTrials.gov

102 Food and Drug Administration Modernization Act (FDAMA) of 1997. www.fda.gov/RegulatoryInformation/ Legislation/FederalFoodDrugandCosmetic
ActFDCAct/SignificantAmendmentstothe FDCAct/FDAMA/default.htm

103 Food and Drug Administration Amendments Act (FDAAA) of 2007.

www.fda.gov/regulatoryinformation/ legislation/federalfooddrugandcosmeticactfdcact/ significantamendmentstothefdcact/ foodanddrugadministrationamendmentsactof $2007 /$ default.htm

104 International Clinical Trials Registry Platform (ICTRP). www.who.int/ictrp/en

105 Clinical Trials Register. www.clinicaltrialsregister.eu

106 UK Clinical Trials Gateway. www.ukctg.nihr.ac.uk/aboutUs.aspx

107 Immunotherapies: Cellular \& Non-Cellular. Prepared by Cellular Therapies Working Group, OCTGT/CBER/FDA. www.ama-assn.org/ama/pub/physicianresources/medical-science/united-statesadopted-names-council/naming-guidelines/ immunotherapies.page

108 Overview of USP efforts to identify naming schemes for tissues and tissue-based products. Weber D, USP Biologics \& Biotechnology: Cell, Gene, and Tissue Therapies Expert Committee. ISCT, 2008 www.celltherapysociety.org/files/PDF/ Meetings/Somatic_2008/Somatic_2008_ Presentations/Product_Nomenclature_Weber. pdf

$109 \mathrm{BIO} /$ BioMedTracker. Clinical Trial Success Rates Study. Hay M, Rosenthal J, Thomas D, Craighead J. BIO CEO \& Investor Conference, 15 February 2011. http://insidebioia.files.wordpress. com/2011/02/bio-ceo-biomedtracker-biostudy-handout-final-2-15-2011.pdf

110 Cell Therapy Blog. Buckler L. http://celltherapyblog.blogspot.co.uk/2011/12/ active-phase-iii-or-iiiii-cel-therapy.html 